\title{
Treatment of patients with primary cutaneous lymphomas - real-life data
}

\author{
Ewa Chmielowska1, 3,4, Aleksandra Grzanka-Gadzińska², Maciej Studziński ${ }^{5}$, Anna Krause1,3, \\ Monika Olejniczak ${ }^{1,3}$, Michał Marjański ${ }^{1}$, Karolina Wróblewska ${ }^{1}$, \\ Małgorzata Sokołowska-Wojdyło 4,5
}

\author{
'Oncologic Center, Bydgoszcz, Poland \\ ${ }^{2}$ Clinic of Dermatology, Bydgoszcz, Poland \\ ${ }^{3}$ Oncologic Hospital, Tomaszów Mazowiecki, Poland \\ ${ }^{4}$ Polish Lymphoma Research Group, Poland \\ ${ }^{5}$ Hospital "Elblaska" Luxmed, Warszawa, Poland \\ ${ }^{6}$ Department of Dermatology, Venerology and Allergology, Medical University of Gdańsk, Poland
}

Background. Primary cutaneous lymphomas $(\mathrm{PCL})$ comprise a heterogeneous group of neoplasms of mature lymphocytes with skin tropism. Although, by definition, these lymphomas are restricted to the skin at the time of diagnosis, during the course of the disease it may involve also lymph nodes and visceral organs. A close cooperation between a dermatologist and oncologist is required to ensure proper treatment. We present in a real-life data on treatment of patients with PCL between dermatology and oncology department.

Material and methods. 104 patients were registered in a joined database of Oncology Department of Oncology Centre in Bydgoszcz and Dermatology Department of Medical University in Toruń between 2007 and 2017. Due to different clinical and prognostic features data from MF/SS (44 patients), non-MF/SS CTCLs and CBCLs were presented separately.

Results. Median overall survival for patients with MF/SS was 76.7 months. Median follow-up time was 5 years.

NOWOTWORY J Oncol 2019; 69, 3-4: 77-82

Key words: cutaneous lymphoma, follow-up data, mycosis fungoides, daily practice

\section{Introduction}

Primary cutaneous lymphomas (PCL) are rare extranodal non-Hodgkin lymphomas, 75\% of them are derived from T lymphocytes (cutaneous T-cell lymphomas, CTCL) and 25\% from B lymphocytes (cutaneous B-cell lymphomas, CBCL) [1-3].

CBCLs are divided into 3 subgroups: primary cutaneous follicle centre lymphoma (PCFCL), primary cutaneous marginal zone lymphoma (PCMZL), and primary cutaneous diffuse large B-cell lymphoma, leg type (PCDLBCL, LT) [1-3]. CTCLs comprise a group of distinct entities with significantly varied clinical, histological and immunophenotypic features and prognoses.

The diagnosis and classification of PCL is based on histological assessment and immunohistochemical staining of an skin biopsy specimen. A prompt diagnosis is often difficult due to $P C L$ s relative rarity and unspecific clinical presentations.

Mycosis fungoides (MF) and its leukemic phase, Sézary Syndrome (SS), is the most predominant subtype of CTCL 53\% [1-4]. MF can mimic different skin conditions, such as eczema, atopic dermatitis, psoriasis, and even other cutaneous lymphomas.

Histological findings are often unspecific and overlap with those of other inflammatory or non-neoplastic diseases so empirical treatment e.g. with topical steroids may hamper the diagnosis. MF has usually an indolent course and a good prognosis. Early-stage MF can be successfully managed by skin-directed therapy, advanced stages of MF and SS require systemic treatment modalities [4]. 
There is a relative scarcity of data regarding the treatment options of advanced stages CTCLs from non-dermatological units in Poland [5-8]. The aim of this paper is to present real-life clinical data on therapeutic collaboration between dermatological and oncological department. The data have been prepared within the framework of the Polish Lymphoma Research Group.

\section{Methods}

104 patients were diagnosed with PCL between 2007 and 2017 in Oncology Centre in Bydgoszcz and Dermatological Department of Medical University in Toruń.

The diagnosis of PCL was made when the clinical features were consistent with histological review and additional tests such as immunophenotyping. The PCL diagnosis was confirmed when lymphomatous infiltration was limited to the skin without any extracutaneous primary lesions found at the moment of diagnosis and subsequent 6 months of follow-up.

Initially, the patients with early stages of PCL were treated with skin-directed therapies such as PUVA or topical steroids. The first line of systemic therapy for advanced stages of PCL was either low-dose interferon alfa 2 beta (subcutaneous injection, 3 million units, 3 times per week) or low-dose methotrexate (orally,20 mg per week). Subsequent treatment options varied widely depending on the patient's condition and drug availability.

Current paper focuses on the retrospective analysis of clinical data of unselected population of 44 patients diagnosed with MF/SS treated in years 2007-2013. 48 patients with MF/SS who were diagnosed after July 2014 were excluded from the analysis due to participation in the observational clinical trial (NCT 0232365). Due to distinct clinical features and prognosis, patients with non-MF/SS CTCLs and CBCLs are presented separately.

Statistical analysis comprised the calculation of overall survival, patients characteristics, previously applied treatment and coexisting comorbidities.

\section{Results}

The number of visits of the patients referred to the Dermatology Department in 2007-2017 with various dermatoses to confirm a suspicion of PCL are presented in table I. A confirmatory diagnosis of PCL was made in 104 patients. The data from 20062009 are not available due to technical reasons. The number of confirmed diagnosis of various types of PCL in 2007-2017 with ratio of non-MF PCLs to MF is presented in table II.

MF/SS was diagnosed in 92 patients (88.46\% of PCLs); 44 subsequent patients treated in 2007-2013 were included into the analysis. The median follow-up time was 5 years.

Table II. The data from Oncologic Centre - the number of new patients with confirmed skin lymphoma. The proportion between more frequent type: MF (mycosis fungoides), SS (Sezary Syndrome) versus other types of skin lymphoma

\begin{tabular}{|c|c|c|}
\hline Year & $\begin{array}{l}\text { Number of new patients } \\
\text { with confirmed skin } \\
\text { lymphoma }\end{array}$ & $\begin{array}{l}\text { Other type skin } \\
\text { lymphoma/ } \\
\text { /MF+SS }\end{array}$ \\
\hline 2007 & 6 & $1 / 5$ \\
\hline 2008 & 4 & $0 / 4$ \\
\hline 2009 & 5 & $0 / 5$ \\
\hline 2010 & 8 & $1 / 7$ \\
\hline 2011 & 14 & $2 / 12$ \\
\hline 2012 & 3 & $1 / 2$ \\
\hline 2013 & 15 & $2 / 13$ \\
\hline 2014 & 8 & $3 / 4$ \\
\hline 2015 & 16 & $2 / 14$ \\
\hline 2016 & 12 & $0 / 12$ \\
\hline 2017 & 13 & $0 / 12$ \\
\hline All & 104 & $12 / 92$ \\
\hline
\end{tabular}

These data comprise the whole 10 years period 2007-2017. Other skin lymphomas are represented both by $B$ cell and $T$ cell lymphoma: the details are shown in table III and IV. The number of diagnosed cutaneous lymphomas with respect to cases of dermatosis with a similar clinical picture (table I) was assessed to emphasise the scale of diagnostic needs in this area in everyday practice

Table I. The number of visits in a dermatologic department caused by dermatoses or inflammatory dermatoses in relation to the number of visits of the patients with CTCL between 2010 and 2017

\begin{tabular}{|lccccccc|} 
Year & $\begin{array}{c}\text { Allergic Con- } \\
\text { tact dermati- } \\
\text { tis L23 }\end{array}$ & $\begin{array}{c}\text { Atopic skin der- } \\
\text { matitis } \\
\text { L20 }\end{array}$ & $\begin{array}{c}\text { Eczema } \\
\text { L30 }\end{array}$ & $\begin{array}{c}\text { Parapsoriasis } \\
\text { L41 }\end{array}$ & $\begin{array}{c}\text { Papulosqu- } \\
\text { amous disor- } \\
\text { ders L44 }\end{array}$ & $\begin{array}{c}\text { Contact der- } \\
\text { matitis } \\
\text { L24 }\end{array}$ & $\begin{array}{c}\text { All inflammatory } \\
\text { dermatoses } \\
\text { MF like }\end{array}$ \\
\hline 2010 & 441 & 147 & 203 & 29 & 16 & 46 & 246 \\
\hline 2011 & 489 & 158 & 139 & 61 & 6 & 125 & 198 \\
\hline 2012 & 529 & 98 & 251 & 48 & 16 & 116 & 186 \\
\hline 2013 & 575 & 40 & 288 & 69 & 14 & 164 & 212 \\
\hline 2014 & 636 & 63 & 323 & 92 & 21 & 137 & 190 \\
\hline 2015 & 796 & 70 & 477 & 115 & 36 & 98 & 219 \\
\hline 2016 & 1263 & 187 & 804 & 137 & 20 & 115 & 184 \\
\hline 2017 & 1489 & 193 & 997 & 160 & 30 & 109 & 140 \\
\hline
\end{tabular}

The data from 2006 to 2009 are not available due to technical reasons. The growing number of civilizational skin diseases resulting from this visits and diagnostic needs draws special attention 
Table III. Clinical data of 44 MF/SS who started the treatment between 2007 to 2013, and have been follow up minimum 5 years

\begin{tabular}{cccccccccc} 
Woman & Men & Age $<60$ & Age $>61$ & MF primary & SS primary & Stage IIB & Stage III & A/B1/not known & B2 \\
\hline 16 & 28 & 20 & 24 & 41 & 3 & 8 & 36 & $22 / 16 / 6$ & 3 \\
\hline
\end{tabular}

A - blood cytometry without any abnormalities, B1 - not clinically significant number of pathologic lymphocytes, B2 - significant number of pathologic lymphocyte

MF/SS was more prevalent in men (63\%) and patients above 61 years (54\%). Most patients (81.8\%) were in stage III at the moment of the initiation of systemic treatment. The summary of clinical characteristics of the patients with MF/ SS is presented in table III. The frequency of comorbidities and other coexisting dermatoses is shown in table IV. Alcohol use disorder was retrospectively diagnosed in $22.72 \%$ of all
MF/SS patients. The summary of data regarding the first line of systemic treatment is presented in table $\mathrm{V}$.

Interferon (INF) as the first-line treatment was used in 36 patients, methotrexate (MTX) was used in 8 patients. The median duration of treatment with interferon was 14 months and the median duration of treatment with methotrexate was 10 months. 23 patients received 2 lines of systemic therapy,

Table IV. The frequency of other skin diseases and comorbidities

\begin{tabular}{cccccccc} 
Atopic dermatitis & $\begin{array}{c}\text { Skin allergy not } \\
\text { specified }\end{array}$ & Parapsoriasis & $\begin{array}{c}\text { Other skin } \\
\text { diseases }\end{array}$ & $\begin{array}{c}\text { Cardio-vascular } \\
\text { comorbidities }\end{array}$ & Diabetes & ZZA \\
\hline 44 & 27 & 17 & 40 & 24 & 10 & 23 \\
\hline
\end{tabular}

ZZA - alcoho

Table V. The types of treatment and response

\begin{tabular}{|c|c|c|c|c|c|}
\hline $\begin{array}{l}\text { Interferon I line/ } \\
\text { /months of therapy }\end{array}$ & Interferon RR & $\begin{array}{l}\text { Methotrexate I line/ } \\
\text { /months of therapy- } \\
\text { medium value }\end{array}$ & Methotrexate RR & SAE-Interferon & SAE-Methotrexate \\
\hline $\begin{array}{l}36 \text { pts } / 3-120 \\
\text { Median: } 14\end{array}$ & CR-8, PR-28 & $\begin{array}{l}8 \text { pts/4-96 } \\
\text { Median: } 10\end{array}$ & $C R-2, P R-6$ & 1 depression & 1 infarctus \\
\hline Death & Alive patients & $\begin{array}{r}\text { Pt } \\
\text { progr } \\
\text { inter }\end{array}$ & $\begin{array}{l}\text { treated to } \\
\text { ssion without } \\
\text { l/median OS }\end{array}$ & $\begin{array}{l}\text { Pts treated to PR and after } \\
\text { progression/median OS }\end{array}$ & $\begin{array}{c}\text { Patients post SCT/ } \\
\text { /with CR }\end{array}$ \\
\hline 14 & 30 & 76.7 months & $\begin{array}{l}4 \mathrm{mts} \text {, median: } \\
4.3 \mathrm{mts}\end{array}$ & 21/6-144 mts, median: $79.1 \mathrm{mts}$ & $4 / 4$ \\
\hline
\end{tabular}

pts - patients, SCT - stem cell transplantation

Table VI. CBCL and non MF/SS CTCL treatment details

\begin{tabular}{|c|c|c|c|c|c|c|c|}
\hline CBCL type/gender & I line & II line & Maintenance & $\begin{array}{l}\text { Observation only/ } \\
\text { /medium } \\
\text { number of visits } \\
\text { per years }\end{array}$ & $\begin{array}{c}\text { Efficacy/ } \\
\text { /I line }\end{array}$ & Relapse & $\begin{array}{l}\text { Time to } \\
\text { Il line }\end{array}$ \\
\hline PCFCL/W & COP & No & No & $\mathrm{No} / 7$ & $C R$ & No & n.a \\
\hline PCFCL/M & No & No & No & Yes/3 & n.a & n.a & n.a \\
\hline PCMZL/K & AC due to breast cancer & No & No & $\mathrm{No} / 12$ & $C R$ & No & n.a \\
\hline PCDLBCL/W & $\mathrm{R}-\mathrm{CHOP}$ & No & No & $\mathrm{No} / 9$ & $C R$ & No & n.a \\
\hline $\mathrm{FL} / \mathrm{W}$ & R-CVP & No & No & $\mathrm{No} / 6$ & $C R$ & No & n.a \\
\hline $\mathrm{FL} / \mathrm{W}$ & $\mathrm{R}-\mathrm{CVP}$ & No & Yes & $\mathrm{No} / 5$ & $C R$ & No & n.a \\
\hline DLBCL/W & $\mathrm{R}-\mathrm{CHOP}$ mini & No & No & $\mathrm{No} / 9$ & SD & Yes & n.a \\
\hline LYP CD30+/W & MTX & n.a & No & $\mathrm{No} / 12$ & $C R$ & No & n.a \\
\hline PCALCL ALK + CD 30+/M & Surgery & n.a & No & Yes/3 & $C R$ & No & n.a \\
\hline PCALCL ALK-CD30+M & MTX/surgery & $\mathrm{ICE}+\mathrm{SCT}$ & No & n.a/12 & $C R$ & Yes & 15 \\
\hline PCALCL ALK+ CD 30+/M & MTX & MTX & No & n.a/6 & $C R$ & No & n.a \\
\hline LYP CD 30-M & MTX/Interferon & Bexarotene & No & $\mathrm{No} / 12$ & SD & Yes & 56 \\
\hline
\end{tabular}

CR - complete remission, PR - partial remission, SD - stabilisation, PD - progression, W - woman, $\mathrm{M}$ - man, PCFCL - primary cutaneous follicle centre lymphoma, PCMZL primary cutaneous marginal zone lymphoma, PCDLBCL LT - primary cutaneous diffuse large B-cell lymphoma (leg type), PCALCL - primary cutaneous anaplastic large cel lymphoma, LYP - lymphomatoid papulosis, n.a - not applicable 
15 patients - 3 lines and 15 patients - more than 3 lines (9 pts -4 lines, 5 pts -5 lines, 1 pt -6 lines). The chemotherapy regimens used for relapsed or refractory disease beyond the second-line therapy were as follows: gemcytabine (10 pts), liposomal doxorubicin (11 pts), cytarabine (4 pts), pralatrexate (1 pt), bexarotene (8 pts).

Stem cell transplant (SCT) was performed in 4 patients after achieving remission after the use of romidepsin as an induction therapy (3 pts - allogeneic SCT, 1 pt - allogeneic SCT). 2 patients participated in Millennium clinical trial and received alisertib and pralatrexate. Overall survival data is presented in table VI.

There were 7 patients with CBCL. Patients with $C B C L$ received rituximab-containing chemotherapy regimens. 1 patient with synchronic and breast cancer was treated with AC chemotherapy with subsequent breast-conserving surgery followed by radiotherapy.

5 patients have had a long-term remission. 2 patients with CBCLS died: 90 year old man due to a cardiovascular disease and 78-year old woman due to the disease progression; patients were diagnosed with lymphomatoid papulosis (CD30+ - 1 pts, CD30- - 1 pts) and 3 patients were diagnosed with primary cutaneous anaplastic large cell lymphoma CD30+ (ALK- - 1 pt, ALK+ - 2 pts).

A patient with PCALCL ALK+ received a complete remission after polychemotherapy and treatment was consolidated by allogeneic HCT. A patient with LyPCD30+, resistant to initial MTX and INF treatment, received bexarotene treatment with long-lasting partial remission despite the need for a significant dose reduction of bexarotene. Tables VI and VII presents clinical course and survival data CBCLS and non MF/SS lymphoma.

\section{Discussion}

CTCLs comprise a group of heterogeneous lymphomas with a varied clinical behaviour. Most CBCLs are indolent lymphomas that infrequently infiltrate extracutaneous sites, have a good prognosis and may be effectively managed with locally targeted therapies. The advanced stages of $C B C L s$ require immunochemotherapy as other nodal non-Hodgkin lymphomas. The data presented in this paper regarding CBCLs and its clinical features are consistent with other reports $[1,2]$. CTCL is the most dominant type of PCL. Most dominant subtypes of CTCL were MF/SS (44 pts), CD30+-lymphomas; other subtypes like PCALCL and LyP were rare (5 pts). Low-dose methotrexate is a frequent first line therapy for multifocal PCALCL with good clinical results and the rate of complete remission near 40\% [9].

Two patients were MTX-resistant and required subsequent therapy. 1 patient was successfully managed by the surgical removal of a skin lesion.

Although MF is the most common type of $\mathrm{PCL}$, the reports regarding treatment options is relatively sparse. A broad spec-

Table VII. Clinical data and overall survival in CBCL and patients with non MF/SS

\begin{tabular}{|c|c|c|c|c|c|c|c|c|}
\hline $\begin{array}{l}\text { Type } \\
\text { PCL }\end{array}$ & Sex & Age & $\begin{array}{l}\text { First } \\
\text { visit }\end{array}$ & $\begin{array}{l}\text { Other skin } \\
\text { diseases }\end{array}$ & Comorbidities & Stage & $\begin{array}{c}\text { Alive } \\
\text { yes or no/OS }\end{array}$ & Date of death \\
\hline PCFCL & W & 59 & V 2007 & Any & $(-)$ & $\begin{array}{c}\text { T4NOMO } \\
\text { Symptoms B+ }\end{array}$ & Yes/141 months & n.a \\
\hline PCFCL & M & 90 & IV 2014 & Any & Dementia & T4N1MO & No/14 months & June 2015 \\
\hline PCMZL & W & 64 & VII 2013 & Any & Breast cancer & T3NOMO & Yes/67 months & n.a \\
\hline $\begin{array}{l}\text { PCDLBCL leg } \\
\text { type }\end{array}$ & W & 49 & IX 2014 & Any & Diabetes & IXA & Yes/54 months & n.a \\
\hline PCFCL & W & 59 & $\times 2015$ & Any & $(-)$ & T4NOMO & Yes/39 months & n.a \\
\hline PCFCL & W & 70 & VII 2014 & Any & Hypertension & T4NOMO & Yes/52 months & n.a \\
\hline $\begin{array}{l}\text { PCDLBCL leg } \\
\text { type }\end{array}$ & W & 78 & ||| 2015 & Any & $\begin{array}{l}\text { Diabetes, } \\
\text { hypretension }\end{array}$ & T4N1M0 & No/8 months & October 2015 \\
\hline LYP CD30+ & W & 64 & ||| 2010 & Hypertension & $\begin{array}{l}\text { Atopic } \\
\text { dermatitis }\end{array}$ & T3NOMO & Yes/106 months & n.a \\
\hline $\begin{array}{l}\text { PCALCL } \\
\text { ALK+ } \\
\text { CD } 30+\end{array}$ & M & 44 & V 2011 & Any & $(-)$ & T1NOMO & Yes/91 months & n.a \\
\hline $\begin{array}{l}\text { PCALCL } \\
\text { ALK- } \\
\text { CD } 30+\end{array}$ & W & 47 & XI 2011 & Any & $(-)$ & T3NOMO & Yes/85 months & n.a \\
\hline $\begin{array}{l}\text { PCALCL } \\
\text { AKL+CD30+ }\end{array}$ & M & 39 & || 2012 & Any & $(-)$ & T3NOMO & Yes/82 months & n.a \\
\hline LYP CD30- & W & 72 & 12013 & $\begin{array}{l}\text { Coronary } \\
\text { disease }\end{array}$ & $\begin{array}{l}\text { Skin allergy not } \\
\text { specified }\end{array}$ & T4N1M0 & Yes/72 months & n.a \\
\hline
\end{tabular}

W - woman, M - man, PCFCL - primary cutaneous follicle centre lymphoma, PCMZL - primary cutaneous marginal zone lymphoma, PCDLBCL LT - primary cutaneous diffuse large B-cell lymphoma (leg type), OS - overall survival, PCALCL - primary cutaneous anaplastic large cell lymphoma, LYP - lymphomatoid papulosis, n.a - not applicable 
trum of clinical features of MF may be initially missed and thus adequate therapeutic measures delayed.

Another problem regarding the treatment of MF is the limited access to novel drugs due to reimbursement decisions. Currently in Poland there is no access to treatment options like romidepsin and other HDAC inhibitors, denileukin diftitox, pegylated liposomal doxorubicin or extracorporeal photopheresis. [13-16]. For an early stage MF confined to the skin, the therapeutic concept is to control symptoms by use of skin-directed therapies e.g. topical agents such as corticosteroids, mechlorethamine, carmustine, retinoids, phototherapy, superficial radiotherapy, and total skin electron beam therapy. Due to chronic and recurrent nature of MF, in advanced stages, repeated systemic treatment are necessary for disease control $[19,20]$. Possible systemic treatment options are: bexarotene, interferon-a, histone deacetylase inhibitors, denileukin diftitox, chemotherapy [13, 19, 21].

Single-agent chemotherapies with a high overall response rate (ORR) are as follows [13-16, 21]: pegylated liposomal doxorubicin (ORR $=88 \%$ in stage IA-IV 88\%), gemcitabine (ORR $=70 \%$ in stage IIB-III), fludarabine (ORR $=55 \%$ in stage IIA-IV) [17]. Fludarabine can be substituted by cytarabine because of its favourable safety profile - it was used in 4 patients as salvage therapy. Allogeneic HCT is currently the curative treatment option advanced and resistant MF/SS for young and otherwise healthy patients $[19,21]$. The median overall survival for advanced stage MF reported in literature (IIB-IVA) is 60 months $[17,21,23]$. In this study median OS was 75 months.

The aim of this analysis was to confront the treatment options recommended in professional guidelines with every-day practice. In the author's opinion, a limited access to the novel drugs and a small number of clinical trials in Poland make many of proposed treatment modalities a not viable option for the Polish population $[17,24]$. Because of the rarity and a varied natural course of the $\mathrm{MF}$, ranging from indolent to highly aggressive, the close cooperation between a dermatologist and an oncologist in important. In Poland there are formal limitations regarding which kind of treatment can be applied by a specific specialist [25]. Recently, radiotherapy has been more frequently used than in the past, but extracorporeal photopheresis is still not available because of reimbursement issues (the exception is GVHD after allo-SCT) [20].

The debate concerning the best way of treatment of these rare lymphoprolfierative disorders is necessary. Researchers hope that increased understanding of the pathogenesis of cutaneous lymphomas with identification of important molecular markers will lead to the development of new targeted therapies and a better effectiveness of the treatment [26].

\section{Conflict of interests: none declared}

\author{
Ewa Chmielowska \\ Oncologic Center \\ ul. Dr I. Romanowskiej 2 \\ 85-796 Bydgoszcz, Poland \\ e-mail:ewacelin@poczta.wprost.pl
}

Received: 27 Jan 2019

Accepted: 13 Sep 2019

\section{References}

1. Bradford PT, Devesa SS, Anderson WF et al. Cutaneous lymphoma incidence patterns in the United States: a population-based study of 3884 cases. Blood. 2009; 113 (21).

2. Imam MH, Shenoy PJ, Flowers $\mathrm{CR}$ et al. Incidence and survival patterns of cutaneous T-cell lymphomas in the United States. Leuk Lymphoma. 2013; 54 (4): 752-759.

3. Quaglino $\mathrm{P}$, Maule $\mathrm{M}$, Prince $\mathrm{HM}$ et al. Global patterns of care in advanced stage mycosis fungoides/Sezary syndrome: a multicenter retrospective follow-up study from the Cutaneous Lymphoma International Consortium. Ann Oncol. 2019; 30 (3): 494.

4. Olek-Hrab K, Silny W. Diagnostics in mycosis fungoides and Sezary syndrome. Rep Pract Oncol Radiother. 2013;19 (2): 72-76.

5. Olek-Hrab K, Maj J, Chmielowska E et al. Methotrexate in the treatment of mycosis fungoides - a multicenter observational study in 79 patients. Eur Rev Med Pharmacol Sci. 2018; 22 (11): 3586-3594.

6. Chmielowska E, Studziński M, Giebel $S$ et al. Follow-up of patients with mycosis fungoides after interferon $\mathrm{a} 2 \mathrm{~b}$ treatment failure. Postępy Dermatol Alergol. 2015; 32 (2): 19.

7. Chmielowska E, Grzanka A, Krause A et al. Safety and efficacy of interferon-alfa $2 \mathrm{~b}$ (IFN) in the treatment of patients with mycosis fungoides. Onkol. Prak. Klin. 2011; 7 (6): 301-310.

8. Adamska K, Olek-Hrab K, Misterska $\mathrm{M}$ et al. Mycosis fungoides: therapeutic difficulties. Postępy Dermatol Alergol. 2015; 32 (5): 404-408.

9. Sokołowska-Wojdyło M, Lech-Marańda E, Placek W et al. Leczenie pierwotnych chłoniaków skóry. Rekomendacje Sekcji Chłoniaków Skóry Polskiej Badawczej Grupy Chłoniaków. Onkol Prakt Klin. 2010; 6: 29-47.

10. Geller S, Myskowski PL, Pulitzer M et al. Cutaneous T-cell lymphoma (CTCL), rare subtypes: five case presentations and review of the literature. Chin Clin Oncol. 2018. [Epub ahead of print]

11. Prince HM, Kim YH, Horwitz SM, ALCANZA study group. Brentuximab vedotinor physician choice in CD30 positive cutaneous T cel lymphoma; an international open-label randomized, phase 3 multicentre trial. Lancet. 2017; 390 ( 10094) 555-566.

12. Sokołowska -Wojdyło M, Walewski J, Jędrzejczk WW et al. Polish expert's opinion concerning brentuximab vedotin in the treatmentof patients with primary cutaneous lymphomas with CD30 expression. Hematologia. 2018; 9: 83-89.

13. Prince HM, Whittaker S, Hopper T. How I treat mycosis fungoides and Sézary syndrome. Blood. 2009;114 (20): 4337-4353.

14. Ross $\mathrm{C}$, Tingsgaard $\mathrm{P}$, Jorgensen $\mathrm{H}$ et al. Interferon treatment of cutaneous T-cell lymphoma. Eur J Haematol. 1993; 51: 63-72.

15. Aviles A, Nambo MJ, Neri N et al. Interferon and low dose methotrexate improve outcome in refractory mycosis fungoides/Sezary syndrome. Cancer Biother Radiopharmaceut. 2007; 22: 836-840.

16. Zinzani PL, Balivia G, Magagnoli M. Gemcitabine treatment in pretreated cutaneous T-cell lymphoma;experience in 44 patients. J Clin Oncol. 2000; 18: 2603-2606.

17. Trautinger F, Eder J, Assaf $C$ et al. European Organisation for Research and Treatment of Cancer consensus recommendations for the treatment of mycosis fungoides/Sézary syndrome - Update 2017. Eur J Cancer. 2017; 77: 57-74.

18. Sokołowska-Wojdyło M, Florek A, Zaucha JM et al. Polish Lymphoma Research Group Experience with Bexarotene in the treatment of cutaneous T-cell lymphoma. Am J Ther. 2016; 23 (3): e749-756.

19. Querfeld C, Zain J, Rosen St. Primary cutaneous T-cell lymphomas: mycosis Fungoides and Sezary syndrome. Cancer Treat Res. 2019; 176: 225-248.

20. Piotrowski T, Fundowicz M, Pawlaczyk M. Total skin electron beam therapy with rotary dual technique as palliative treatment for mycosis Fungoides. In Vivo. 2018; 32 (3): 517-522.

21. Whittaker SJ, Foss FM. Efficacy and tolerability of currently available therapies for the mycosis fungoides and Sezary syndrome variants of cutaneous T-cell lymphoma. Cancer Treat Rev. 2007; 33 (2): 146-160.

22. Martinez-Escala ME, Kantor RW, Cices A, et al. CD8+ mycosis fungoides: a low-grade lymphoproliferative disorder. J Am Acad Dermatol. 2017; 77: 489-496.

23. Jawed SI, Myskowski PL, Horwitz S et al. Primary cutaneous T-cell lymphoma (mycosis fungoides and Sézary syndrome): part II. Prognosis, management, and future directions. J Am Acad Dermatol. 2014; 70 (2): 223.e1-17 
24. Foss FM, Girardi M. Mycosis Fungoides and Sezary syndrome. Hematol Oncol Clin North Am. 2017; 31 (2): 297-231.

25. Berg S, Villasenor-Park J, Haun $P$ et al Multidisciplinary management of mycosis Fungoides/Sézary syndrome. Curr Hematol Malig Rep. 2017; 12 (3): 234-243.
26. Adult treatment editorial board. Mycosis Fungoides (including Sézary syndrome) treatment $\left(\mathrm{PDQ}^{\oplus}\right)$ : Patient version. PDQ cancer information summaries [Internet]. Bethesda (MD): National Cancer Institute (US); 2002-2017, Sep 7. 